\title{
DIAGNÓSTICO SISTÊMICO E PARTICIPATIVO DAS COMUNIDADES DO MÉDIO MARACÁ (AP): PREPARAÇÃO PARA INSERÇÃO DE ENERGIA ELÉTRICA ALTERNATIVA NO ÂMBITO DO PROGRAMA "LUZ PARA TODOS"1 SYSTEMIC AND PARTICIPATORY DIAGNOSIS OF MÉDIO MARACÁ (AP) COMMUNITIES: PREPARING FOR ALTERNATIVE ELECTIRC ENERGY INTEGRATION IN "LIGHT FOR ALL" PROGRAM
}

\author{
Alexandre Maduro-Abreu \\ Centro de Pesquisa em Gestão, Inovação e Sustentabilidade - CPGIS da Universidade de \\ Brasília, Brasília (DF), Brasil
}

Data de recebimento: $20-03-2014$

Data de aceite: 18-05-2015

\section{Antônio César Pinho Brasil Jr}

Faculdade de Tecnologia da Universidade de Brasília, Braślia (DF), Brasil

\section{Elimar Pinheiro Nascimento}

Centro de Desenvolvimento Sustentável da Universidade de Brasília, Brasília (DF), Brasil

\section{Mireya Eugenia Valencia Perafan}

Centro de Pesquisa em Gestão, Inovação e Sustentabilidade da Universidade de Brasília، Brasília (DF), Brasil

\section{Antônio Nascimento Jr}

Centro de Pesquisa em Gestão, Inovação e Sustentabilidade da Universidade de Brasília, Brasília (DF), Brasil

\section{RESUMO}

Diante do desafio da universalização da energia elétrica, o governo demonstra interesse em assumir a responsabilidade de investir em tecnologias que viabilizem a geração de eletricidade em comunidades isoladas e, concomitantemente, prepará - las para utilizar a energia de forma produtiva. O presente trabalho, resultado de estudos realizados com comunidades do Médio Maracá do Projeto de Assentamento Extrativista (PAE) de Maracá, no município de Mazagão do Estado do Amapá, apresenta a metodologia Gestão Sistêmica e Participativa Local (GSPL), que foi formulada para apoiar a comunidade no processo de gestão local a partir da inserção da energia. O objetivo principal é demonstrar os resultados do diagnóstico realizado na comunidade e apontar as ações necessárias para: a) produzir bens e serviços que melhorem a qualidade de vida da população local, particularmente de sua renda familiar, b) a manutenção do funcionamento da tecnologia de suprimento e c) a utilização da energia em atividades para o desenvolvimento social. Para a realização do diagnóstico foram realizados levantamento bibliográfico sobre trabalhos realizados na comunidade, entrevistas e aplicação de questionários a moradores da comunidade.

Palavras-chave: Energia alternativa; gestão local; diagnóstico sistêmico e participativo; comunidades isoladas.

\section{ABSTRACT}

Faced with the challenge of universalization of electricity, the government demonstrates interest in taking over the responsibility to invest in technologies that allow the generation of electricity in isolated communities and simultaneously prepare them to use energy productively. This study, the result of studies of Médio Maracá communities of Extractive Settlement Project (PAE) of Maracá in the city of Mazagão, in the state of Amapá, presents the methodology Systemic Management and Participatory Local (GSPL), which was formulated to support the community in local management process from the insertion of energy. The main objective is to demonstrate the results of the analysis made in the community and point out the necessary actions to: a) produce goods and services that improve the quality of life of local population, particularly of their family income, b) maintaining the operation of technology supply and c) the use of energy in activities for social development. For the diagnosis were performed literature on work in the community, interviews and questionnaires to community residents.

Keywords: Alternative energy; local governance; participative and systemic diagnosis; remote communities.

Endereço dos autores:

\begin{tabular}{lll}
\hline $\begin{array}{l}\text { Alexandre Maduro-Abreu } \\
\text { alexmaduro@ig.com.br }\end{array}$ & $\begin{array}{l}\text { Alexandre Maduro-Abreu } \\
\text { alexmaduro@ig.com.br }\end{array}$ & $\begin{array}{l}\text { Antônio César Pinho Brasil Jr } \\
\text { brasiljr@unb.br }\end{array}$ \\
$\begin{array}{l}\text { Elimar Pinheiro Nascimento } \\
\text { elimarcds@gmail.com }\end{array}$ & $\begin{array}{l}\text { Mireya Eugenia Valencia Perafan } \\
\text { mireya_eugenia@hotmail.com }\end{array}$ & $\begin{array}{l}\text { Antônio Nascimento Jr } \\
\text { anjunior@unb.br }\end{array}$ \\
\hline
\end{tabular}

1 Versão preliminar apresentada no XIV Congreso Latino-Iberoamericano de Gestión Tecnológica - ALTEC 2011, em Lima, Peru. 


\section{INTRODUÇÃO}

O governo brasileiro tem consciência da dívida social para com as comunidades isoladas que não têm acesso à energia elétrica e aos bens e serviços consequentes que ela permite. Desde os anos de 1960, quando o Brasil priorizou a matriz hídrica como fonte primária de eletricidade, vem havendo um aumento substancial de investimentos para a construção de hidrelétricas. A geração centralizada de energia contribuiu para aumentar as desigualdades socioeconômicas entre as regiões do país, já que as localidades beneficiadas pelas extensões das grandes redes eram caracterizadas pela potencialidade de consumo, crescimento econômico e capacidade de pagamento dos serviços de fornecimento de eletricidade.

Ao contrário, as comunidades isoladas são assentamentos humanos com pouca densidade populacional, baixo nível de atividades econômicas, difícil acesso e dispersas em grandes áreas. Dessa forma, pela incipiência de consumo e incapacidade de pagamento dos serviços de fornecimento de energia inviabilizou-se e permanece impraticável a extensão da rede elétrica até regiões remotas. Com isso, torna-se necessário a utilização de tecnologias de suprimento alternativas de geração de energia para atender às demandas destas populações (VAN ELS et al., 2012; ATHAYDE et.al., 2001).

Essas tecnologias são sistemas descentralizados de pequeno porte para soluções pontuais e de pequena escala, pois geram uma quantidade limitada de eletricidade. No entanto, são possibilidades pelas quais se podem optar para contribuir com a promoção do desenvolvimento sustentável de comunidades isoladas (VAN ELS et al., 2012; ATHAYDE et al., 2001).

A dívida social do Estado para com as comunidades isoladas foi reconhecida publicamente com a promulgação da lei $n^{\circ} 10.438$, em 26 de abril de 2002, que obrigou o Estado a promover a universalização dos serviços de energia elétrica no país.
Mais adiante, com a promulgação do decreto $n^{\circ}$ 4.783, de 11 de novembro de 2003, foi instituído o programa Luz para todos, destinado a propiciar o fornecimento de eletricidade às comunidades ainda não atendidas por esse serviço público - algo em torno de 2.000 .000 (dois milhões) de novos atendimentos.

O Manual de Operacionalização do Programa (MOP) (2003) define a utilização das tecnologias de suprimento e fontes primárias alternativas para atender as demandas dessas populações. É previsto o uso de pequenas, micro e mini centrais hidrelétricas - incluindo hidrocinética -, pequenas centrais térmicas a diesel ou biomassa, sistemas providos de energia solar ou eólica e sistemas híbridos, resultantes da combinação de uma ou mais das seguintes fontes primárias: solar, eólica, biomassa, hídrica e/ou diesel. Todavia, além da necessidade de encontrar soluções tecnológicas, as experiências têm demonstrado que a inserção de eletricidade nas comunidades isoladas não se sustenta também por não contribuir efetivamente para o desenvolvimento local. No período em que está disponível favorece a abertura de bares e compras de bens de consumo. Quando possibilita o incremento da economia, exclui parte da comunidade do processo produtivo formal (VAN ELS et al., 2012; ATHAYDE et al., 2001).

Destaca-se no MOP (2003) a discussão sobre a importância da energia para as comunidades isoladas, a utilização de um planejamento participativo para definir o seu uso e a perspectiva sistêmica para compreender as dinâmicas locais. A energia elétrica é o vetor precípuo para o desenvolvimento das comunidades isoladas. Ela deve ser entendida como insumo econômico e social, capaz de ativar processos produtivos locais, como incrementar os já existentes, e também propiciar direitos e benefícios básicos, como água potável, conservação de alimentos, medicamentos, educação, entre outros. Contudo, a inserção de eletricidade deve estar subsidiada pelo planejamento do desenvolvimento da 
comunidade, assim como a construção de um modelo de gestão local.

A participação da comunidade é condição imperativa em todo processo. É insensato acreditar que o governo ou as suas estruturas de planejamento e gestão possam definir sozinhos as potencialidades e necessidades de uma comunidade. Por outro lado, é também insensato imaginar que a comunidade possa fazer isso sozinha. É preciso a parceria dos conhecimentos técnicos e tradicionais, objetivando consolidar um processo democrático e sustentável de desenvolvimento local (DEMO, 1180; BUARQUE, 2002).

Além de se pensar um processo participativo, é necessário abordá-lo de forma sistêmica, ou seja, voltado para a consideração do todo, mas também abordando as partes contidas neste todo, representando-as e analisando suas interações. À luz da sustentabilidade, o desenvolvimento deve prever a necessidade de se compatibilizar os ganhos e perdas entre as diversas dimensões da sociedade, ao contrário do modelo dominante, que despreza a possibilidade das vantagens econômicas em causar declínios sociais, ecológicos, e assim por diante.

Diante do desafio de viabilizar a geração de eletricidade em comunidades isoladas e prepará -las para utilizar a energia de forma produtiva ao mesmo tempo, o Ministério de Minas e Energia (MME) e o Conselho Nacional de Desenvolvimento Científico e Tecnológico (CNPq) lançaram o Edital CT-Energ/MME/CNPq XXXX, que tinha como objetivo implementar tecnologias alternativas de geração de energia elétrica, e propor soluções para o desenvolvimento sustentável de comunidades isoladas na Amazônia Legal apoiadas por uma metodologia de gestão local.

Para atender as exigências deste edital, elaborou-se e foi aprovado um projeto para se trabalhar com as comunidades do Médio Maracá, localizadas no Projeto de Assentamento Extrativista (PAE) de Maracá, no município de Mazagão, no Estado do Amapá. O projeto teve início em 2005 e foi concluído em 2008. No entanto, houve acompanhamento e apoio à comunidade para implementação das ações elaboradas até o ano de 2011. É importante ressaltar que apesar da literatura de um modo geral, assim como o MOP (2003), enfatizar conceitos como modelo de gestão local, participação da comunidade, visão sistêmica e desenvolvimento sustentável, a literatura sobre o tema carece de estudos aplicados que os considerem.

Ao contrário, o presente trabalho pretende apresentar parte dos resultados alcançados com o projeto executado no PAE Maracá. Em especial, apresentar a metodologia Gestão Sistêmica e Participativa Local (GSPL), que foi formulada para apoiar a comunidade no processo de gestão local a partir da inserção da energia e orientou a execução do projeto. A GSPL também apresentou como demonstrar os resultados do diagnóstico realizado na comunidade e apontar as ações formuladas para: a) produzir bens e serviços que melhorem a qualidade de vida da população local, particularmente de sua renda familiar; b) a manutenção do funcionamento da tecnologia de suprimento; e c) a utilização da energia em atividades para o desenvolvimento social.

\section{FUNDAMENTAÇÃO TEÓRICA: GESTÃO SISTÊMICA E PARTICIPATIVA LOCAL - GSPL}

A GSPL foi elaborada a partir de pressupostos da visão sistêmica, em especial estrutura aberta, interdependência e processamento (BERTALANFFY, 1976; CAPRA, 1997; GEORGESCU-ROEGEN, 1993) do enfoque participativo (BUARQUE, 2002; MATUS, 1997; PUTNAM, 2002; DEMO, 1980), da sustentabilidade (SACHS, 1993; 2000; REDCLIFT, 1995) e da gestão como um processo amplo de fases interdependentes (MEGGINGSON et al., 1998) Inicialmente, a metodologia parte da distinção do sistema de objeto de gestão (comunidade), 


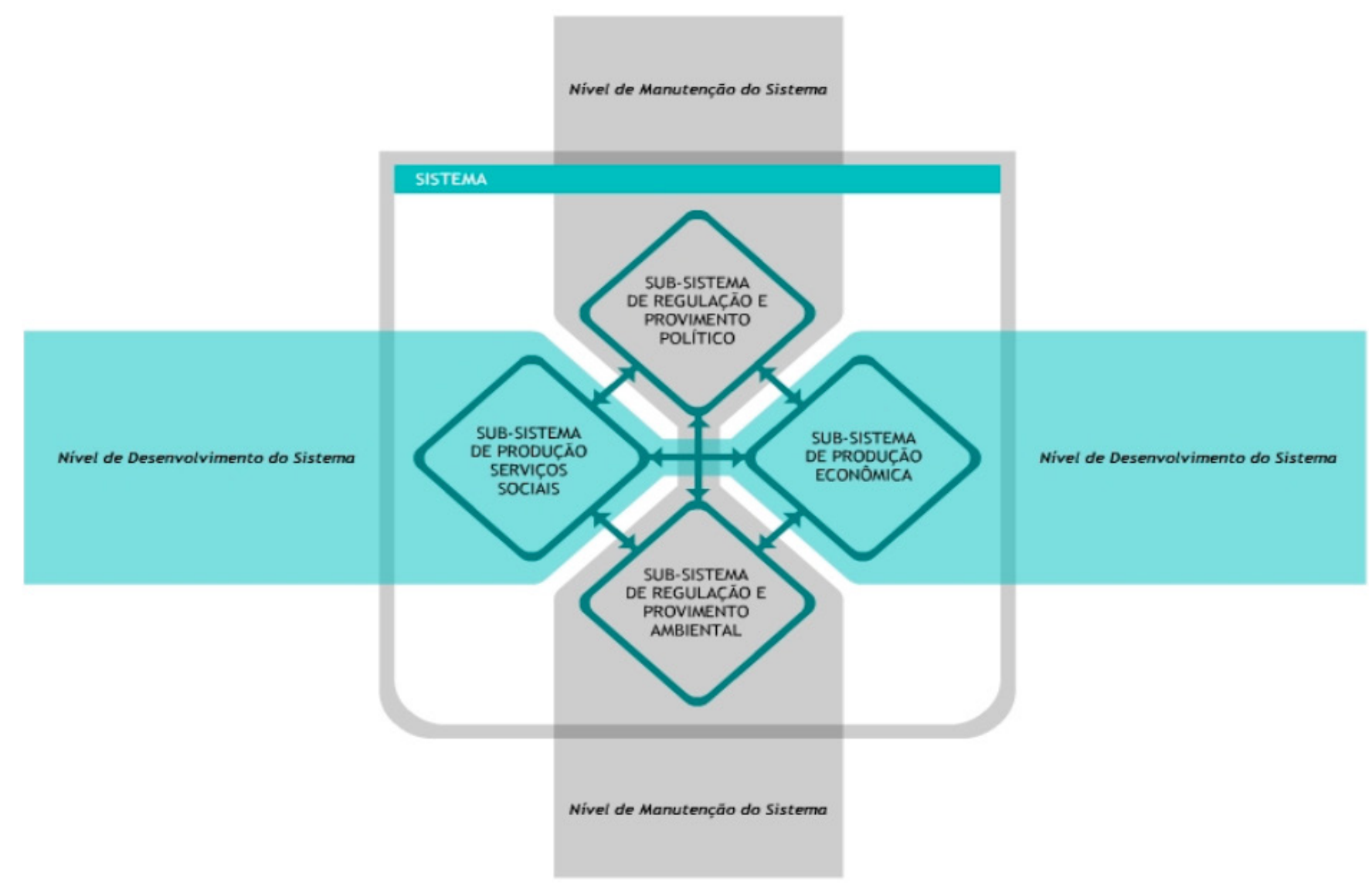

Figura 1 - Diagrama de representação de uma comunidade como sistema a partir dos níveis e funções para o desenvolvimento sustentável local

Fonte: Maduro-Abreu (2005).

em especial definindo seus níveis funcionais. Não à luz de comando, verticalização e poder, mas em sentido transversal, sob o enfoque das funções necessárias para a sustentabilidade do sistema. A partir destas funções, a GSPL prevê um nível de manutenção e um nível de desenvolvimento do sistema.

O nível de manutenção compreende os subsistemas que atuam para prover o sistema de condições internas (estruturais) para o desenvolvimento e para a autorregulação, preservando o equilíbrio e mantendo o sistema direcionado para a consecução de seus objetivos. O nível de desenvolvimento do sistema é constituído de subsistemas que operam para o incremento de processos produtivos locais e prestam, efetivamente, serviços de apoio, formação, capacitação, saúde, segurança, entre outros, na comunidade.
Dadas as condições estruturais do sistema e os objetivos individuais de cada subsistema, há tensões e conflitos - trade-offs -, o que pode gerar ganhos para um subsistema e perdas para outros, assim como o declínio do sistema. O nível de manutenção é o nível funcional requerido para o equilíbrio de uma comunidade, em que estão os subsistemas de regulação e provimento do sistema, responsáveis por traçar os objetivos, delimitar fronteiras, prover condições internas e regular as relações.

O nível de manutenção é composto por dois subsistemas. O subsistema de regulação e provimento, que a partir de atividades e decisões políticas desempenha funções para o equilíbrio (dinâmico) do sistema e proporciona condições socioeconômicas para o seu desenvolvimento e o subsistema de regulação e provimento ambiental, que a partir de atividades ecossistêmicas, regula as 
atividades socioeconômicas e provê o sistema de condições para o desenvolvimento.

O subsistema de regulação e provimento político é constituído pelos arranjos locais que possibilitam à comunidade participar do processo de desenvolvimento e do processo político (PECQUEUR, 2001; PIRES, 2007; PIRES; MÜLLER; VERDI, 2006; SACHS, 2003) Deve-se reconhecer a arquitetura jurídico-política da comunidade, ou seja, as instituições públicas, instâncias de participação, formas de participação (BUARQUE, 2002) e as organizações que contribuem para prover condições estruturais para a produção socioeconômica.

O subsistema de regulação e provimento ambiental é constituído pelo próprio meio ambiente. Entretanto, a função de provimento de recursos naturais, principalmente para a produção econômica, não pode mais ser vista por meio do conceito de vantagens comparativas - dotações desses recursos como base para processos produtivos aliados a vocação local de produção. Isso não significa que a disponibilidade de recursos naturais não tenha importância para uma economia local, mas indica que o seu aproveitamento e a sua utilização devem incorporar massas crescentes de conhecimento e informação, contidas nas tecnologias e nos processos, principalmente como forma de garantir sua qualidade e sustentabilidade (BUARQUE, 2002; LEFF, 2001).

A educação, como alerta Demo (1980), é o vetor principal para a capacitação de recursos humanos, disseminação do conhecimento, consolidação de base tecnológica e para a formação de cidadãos políticos, capazes de participar das decisões em sua comunidade. Socialmente, a educação, de forma isolada, não é condição suficiente para isso. Ela deve estar necessariamente complementada com o acesso à saúde, condições higiênico-sanitárias, bem como outros serviços sociais. Assim, como prerrogativa para a sustentabilidade, a GSPL identifica um subsistema de produção de serviços sociais (serviços de saúde, educação, segurança e outros, sejam públicos ou privados) na comunidade como integrantes do nível funcional de desenvolvimento.

Cabe ao subsistema de produção de serviços sociais, constituído por quaisquer formas e instâncias de participação, organizações públicas, privadas e não governamentais e agentes sociais, desempenhar a função de produzir serviços para a disseminação do conhecimento e fortalecimento cultural, construção de massa crítica e práticas locais, consciência política e ambiental, manutenção da saúde e higiene, entre outras potencialidades e necessidades socioculturais da comunidade (SACHS, 1991 (FONTES; EICHNER, 2001).

A cultura aparece como amálgama da formação social, pois se pressupõe que os conhecimentos tradicionais, relações e práticas locais são necessários para a formação do indivíduo. Está se falando, aqui, da complementaridade dos conhecimentos disciplinares e dos tradicionais, culturalmente construídos, ou seja, de uma formação transdisciplinar.

As funções para desenvolvimento do sistema não se restringem à produção de serviços sociais; é imprescindível que se produzam bens e serviços para transações comerciais ao mesmo tempo. Nesse sentido, destaca-se o subsistema de produção econômica. A arquitetura desse sistema também exige a distinção de formas de participação conjunta, entidades privadas, públicas e não governamentais e organizações (formais ou informais) que atuem nos processos produtivos locais.

Somente para efeito de comparação, o entendimento do subsistema de produção econômica da forma como apresentado pela GSPL remete ao que atualmente é rotulado como Arranjo Produtivo Local (APL).

Arranjos produtivos são aglomerações de empresas localizadas em um mesmo território, que apresentam especialização produtiva e mantêm algum vínculo de articulação, interação, cooperação e aprendizagem 
entre si e com outros atores locais (PROJETO PROMOS/ SEBRAE/BID, 2004, p. 17).

O conceito de APL (SACHS, 2003; LASTRES; CASSIOLATO, 2003) é coerente com os critérios utilizados pela GSPL para a classificação de subsistemas de uma comunidade, pois enfatiza a interação e interdependência de organizações para desempenhar uma função específica. No caso dos $A P L$, essa função é a produção econômica. A noção de arranjo, aplicada a processos produtivos locais, também pode ser, por princípio, estendida a outros subsistemas. Tal como foram estruturados, tanto o subsistema de regulação e provimento político quanto o de produção de serviços sociais mantêm as características mencionadas, ou seja, rede de organizações que desempenham funções para a consecução de objetivos.

Assim, tem-se, na Figura 1, uma comunidade representada como um sistema estruturado, sob a ótica de uma metodologia de gestão que orienta a distinção da comunidade em estudo a partir de propriedades sistêmicas e coerentes com os princípios para o desenvolvimento sustentável (objetivo). Privilegia-se a identificação de níveis funcionais e objetivos do sistema e dos subsistemas, assim como as partes que compõem os subsistemas, responsáveis por desempenharem as funções e atingir os objetivos de cada subsistema e do sistema como um todo.

A GSPL também considera o ambiente externo que envolve e se relaciona com a comunidade. Diante da amplitude de influências que podem ser geradas pelo ambiente externo, foram criados parâmetros para identificar as interações mais intensas e reconhecidas pela população. Para isso, apoiou-se nos conceitos de ambiente de tarefa e ambiente geral (DAFT, 1999).

O ambiente de tarefa caracteriza-se por ser o estrato do supra-sistema que efetivamente relaciona-se com a comunidade. Ele é fundamental para se ter o alcance da interação entre o sistema e o supra-sistema. Por seu intermédio, reconhecemse os componentes que têm influências realmente relevantes na comunidade. Pressupõe-se que as organizações e formas de participação que compõem os subsistemas locais mantêm relações de interdependência com outras que fazem parte do supra-sistema.

Para a caracterização do ambiente de tarefa identificam-se as organizações sociais externas que se relacionam diretamente com a comunidade, sejam privadas, não governamentais ou públicas (federais, estaduais e/ou municipais), descrevendo as ações e processos gerados na localidade. $\mathrm{O}$ ambiente geral compreende a natureza dos insumos que entram no sistema, gerados a partir das relações entre as partes do subsistema e as organizações que estão no ambiente de tarefa. Os insumos podem ser de natureza social, econômica, política, tecnológica, legal, ecológica, cultural, religiosa, entre outros.

Além da distinção dos subsistemas e da estrutura do suprassistema, é importante considerar a construção de uma organização de gestão local. A GSPL aponta para a consolidação de uma entidade de direito privado com participação de representantes do poder estatal e da sociedade civil e política. Pode-se representar uma comunidade como orientação à implementação da Gestão Sistêmica e Participativa Local (GSPL), como na Figura 2 a seguir.

Finalmente, a GSPL é definida como um modelo estrutural que orienta a distinção e representação das organizações de uma comunidade e das suas relações com organizações externas, arranjando-as em subsistemas funcionais necessários para o desenvolvimento sustentável local, o qual se assenta à metodologia. Além disso, é importante tomar a GSPL como um processo retroalimentado, que permite que os atores sociais participem da gestão e considerem a interdependência das partes do sistema. Esse processo de gestão tem como instrumento de ação principal o planejamento, que 


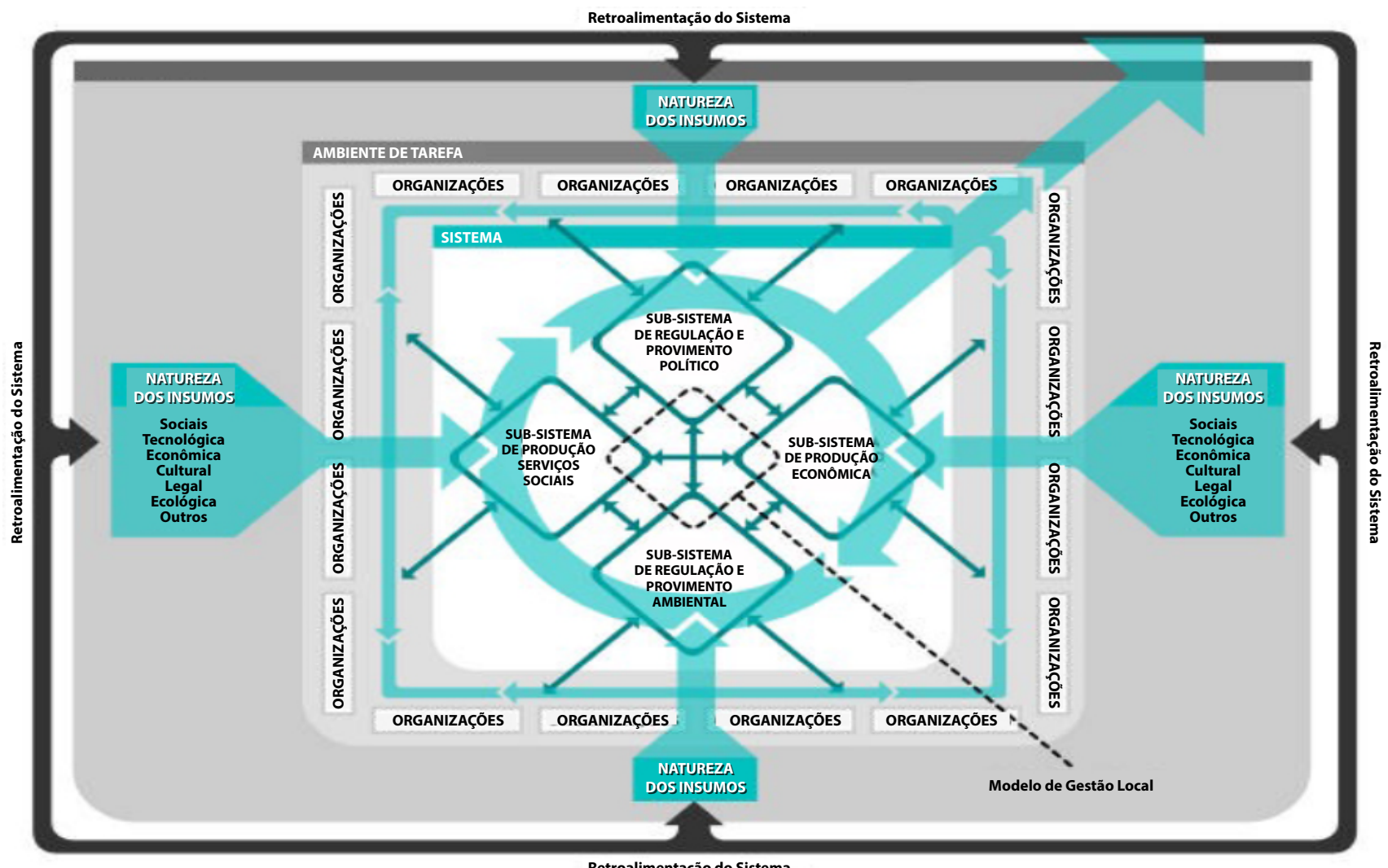

Figura 2 - Representação da GSPL considerando a inserção do modelo de gestão local Fonte: Maduro-Abreu (2005).

se apoia no modelo estrutural da metodologia. A execução do que foi planejado e o monitoramento e avaliação das ações são partes integrantes e exigidas para a realimentação da GSPL. Em resumo, os passos metodológicos centrais para implementação deste processo são: i) diagnóstico sistêmico e participativo; ii) elaboração do plano de gestão sistêmica e participativa local; iii) implementação de ações; iv) monitoramento e avaliação dos resultados; v) retroalimentação do processo de gestão.

\section{PROCEDIMENTOS METODOLÓGICOS}

A pesquisa se caracterizou, quanto aos objetivos, por ser exploratória e descritiva. Quanto aos procedimentos técnicos, realizou-se um estudo de caso, em 2005, nas comunidades do Médio Maracá, localizadas no Projeto de Assentamento
Extrativista (PAE) de Maracá, na Amazônia legal, no município de Mazagão, no estado do Amapá. Os instrumentos utilizados foram um levantamento bibliográfico de trabalhos produzidos na/sobre as comunidades e entrevistas individuais (quatro chefes de família, o presidente da Associação de Trabalhadores Agroextrativistas do Vale do Rio Maracá (ATEX-MA) e um representante da Escola Família Rural) e em grupo com representantes locais (dois encontros com cinco moradores não chefes de família) durante o mês de agosto. Além disso, tabularam-se os dados do questionário de recadastramento da comunidade. Este questionário, com estrutura semelhante ao utilizado no levantamento socioeconômico em 1994, validado por Filocreão e Little (1994), foi aplicado durante os meses de janeiro e fevereiro de 2005 nos 250 chefes de família da comunidade. Foi realizado também, nos meses de abril (período de seca) e outubro (período de 
cheia) de 2004, o levantamento e confirmação dos dados hidrológicos coletados, em 2002, em estudo anterior, na mesma área. Ressalta-se que o projeto estendeu-se até o ano de 2010, pois além do diagnóstico foram realizadas a formulação, execução e monitoramento das ações implementadas na comunidade.

\section{RESULTADOS E DISCUSSÕES}

A partir de 1990, com a possibilidade de legalizar as terras ocupadas por comunidades agroextrativistas, o Instituto Nacional de Colonização e Reforma Agrária (INCRA) iniciou o levantamento de áreas passíveis de se tornarem Projetos Agroextrativistas (PAE). Especificamente no Amapá existiam, às margens do Rio Maracá, 363.500 ha de terras desapropriadas no ano de $1983^{1}$, por ato do próprio INCRA. O INCRA de Amapá analisou a área e elaborou um plano preliminar, optando pela criação de três PAE. Assim, por intermédio das portarias INCRA número 1440, 1441 e 1442 de outubro de 1988, foram criados os PAE Maracá I (área total de 75.000 ha), Maracá II (área total de 22.500 ha) e Maracá III (área total de 266.000).

Posteriormente, através da portaria/GM/número 017 de 28 de abril de 1997, foram redefinidos a área e o número de famílias beneficiadas, bem como unificados os PAE de Maracá I, II e III, recebendo a denominação de Projeto de Assentamento Agroextrativista Maracá. A portaria de retificação do INCRA foi publicada em dezembro de 2002, onde constam essas alterações. Assim, a área de 363.500 ha passa a ser de 569.208.540ha e as famílias que inicialmente eram estimadas em 1.068 unidades passaram a ser de 939 famílias agroextrativistas.

\footnotetext{
1 As terras foram desapropriadas pelos Decretos $n^{\circ} 86.236$, de 29/09/1981, e n 88.359, de 07/08/1983, para fins de reforma agrária, mantendo-se na área a população tradicional existente.
}

Entende-se que o PAE é uma modalidade de assentamento destinado às populações tradicionais para que explorem os recursos naturais de forma sustentável. Deve ser implantado em terras públicas, transferindo, através de concessão do direito de uso, a gestão da área para as populações assentadas. No entanto, além da implantação, o INCRA deve manter a supervisão do desenvolvimento do projeto e viabilizar a elaboração de um plano de utilização e de um plano de desenvolvimento do assentamento.

Para a gestão do PAE de Maracá foi criada, em 1991, a Associação de Trabalhadores Agroextrativistas do Vale do Rio Maracá (ATEX-MA), que possui, atualmente, a concessão de direito real de uso do assentamento. A elaboração e assinatura do contrato, em 1997, só foram possíveis após o cadastramento da população beneficiária - realizado concomitantemente ao levantamento socioeconômico - e a elaboração do Plano de Utilização, finalizado em 1995. O Plano de Desenvolvimento do Assentamento Maracá (PDA) foi concluído somente no ano de 2004. O INCRA e a ATEX-MA e suas relações políticas e jurídicas constituem o subsistema de regulação e provimento político da comunidade do PAE de Maracá.

Mesmo com a unificação do projeto de assentamento, percebe-se que os trabalhos realizados na área, bem como a própria comunidade, entendem que há uma divisão entre as populações de Maracá I, II e III, por ela denominadas Baixo, Médio e Alto Maracá, respectivamente. O PDA, elaborado após a unificação do assentamento, em alguns momentos considera-o uma unidade. Em outros momentos, devido a propriedades geoambientais, analisa -o separadamente. As pesquisas bibliográficas e as entrevistas com os atores sociais conduziram, para efeito desta pesquisa, a seguinte delimitação do Médio Maracá:

O levantamento e análise de informações para o diagnóstico dos subsistemas previstos pela GSPL foi realizado a partir da tabulação dos dados 


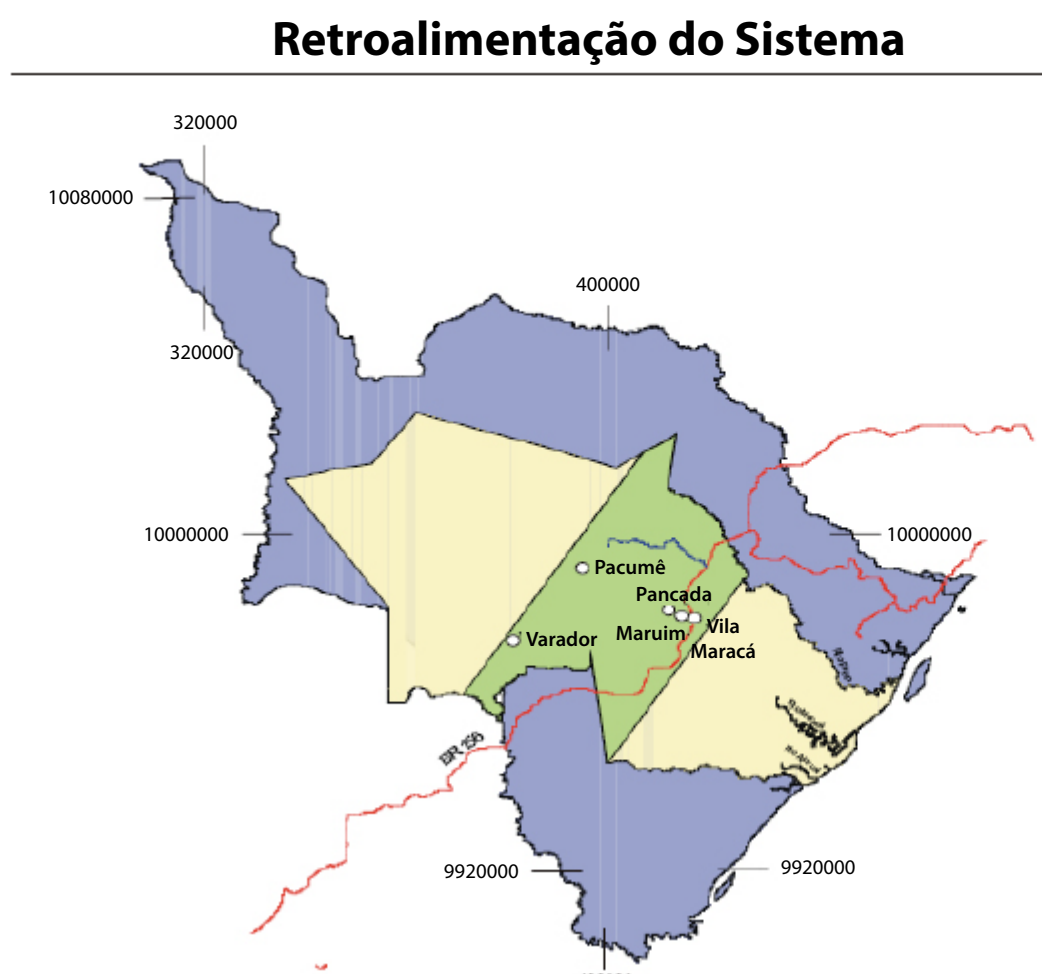

Figura 3 - Representação da área de estudo - Vila de Maracá (Médio Maracá)

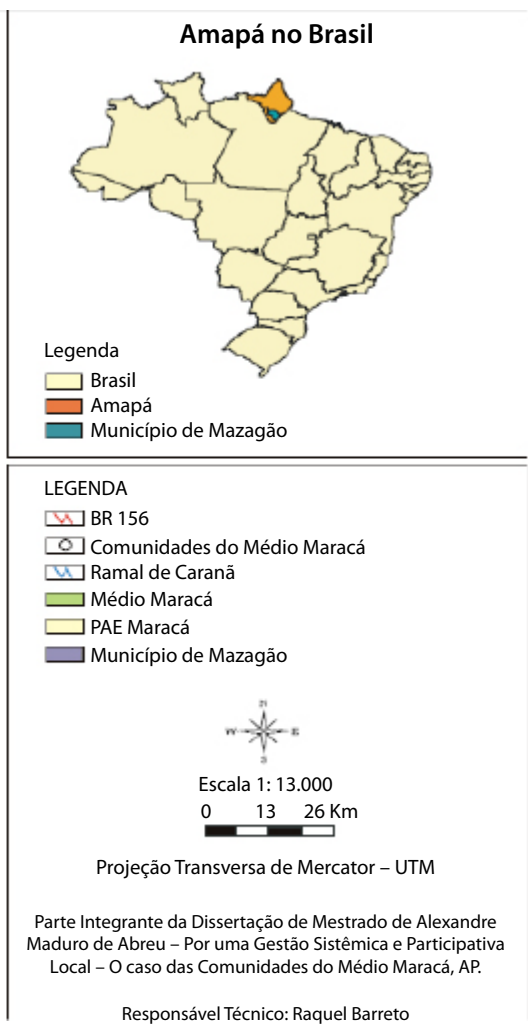

Fonte: Maduro-Abreu (2005)

obtidos em um questionário aplicado na comunidade em 2005, comparando-os com os resultados do Levantamento Sócio-Econômico dos PAE Maracá I, II e III de 1994, realizado por Filocreão e Little (1994). Além disso, há resultados das observações e entrevistas individuais e coletivas realizados com os moradores do Médio Maracá.

Conforme explicitado anteriormente, o subsistema de provimento ambiental tem por função fornecer condições para o desenvolvimento da localidade, incluindo-se aí a geração de energia. Dentre as possibilidades, destaca-se a disponibilidade de recursos hídricos em Maracá. Esta condição foi verificada a partir do levantamento hidrológico realizado no local pela Universidade de Braśília, financiado pelo Ministério do Meio Ambiente (MMA) em 2002.

Em expedição pelo Rio Maracá, no mês de abril ${ }^{2}$ de 2002, para medição da largura, profundidade e

\footnotetext{
2 No mês de abril as águas dos rios na região estão com os níveis baixos, é considerada a época da seca.
}

velocidade das águas em diferentes pontos, constatou-se que a Cachoeira do Caranã seria o local ideal para a instalação de uma Turbina Hidrocinética. Além de profundidade e velocidade suficientes, está próxima ao ramal em construção que deverá facilitar o escoamento da produção e ao posto de armazenamento, já utilizado por parte da população na coleta da castanha. No mês de outubro do mesmo ano foi realizada outra expedição para levantamento do perfil hidrológico no período das águas.

Segundo Belas, Els e Campos (2002), o dimensionamento da potência hidráulica é feito a partir da profundidade do rio na época da seca. Diante das medições realizadas, dois pontos - com perfis diferentes - foram apontados como potenciais para a instalação da Turbina em Caranã. O potencial hidráulico disponível é calculado pela fórmula $P H D=500 \times K B \times(V) 3 \times$ Área $=232 \times V 3 \times D 2$ (watts), onde PHD é o potencial hidráulico disponível, KB é a constante de Betz (16/22), Área é a 


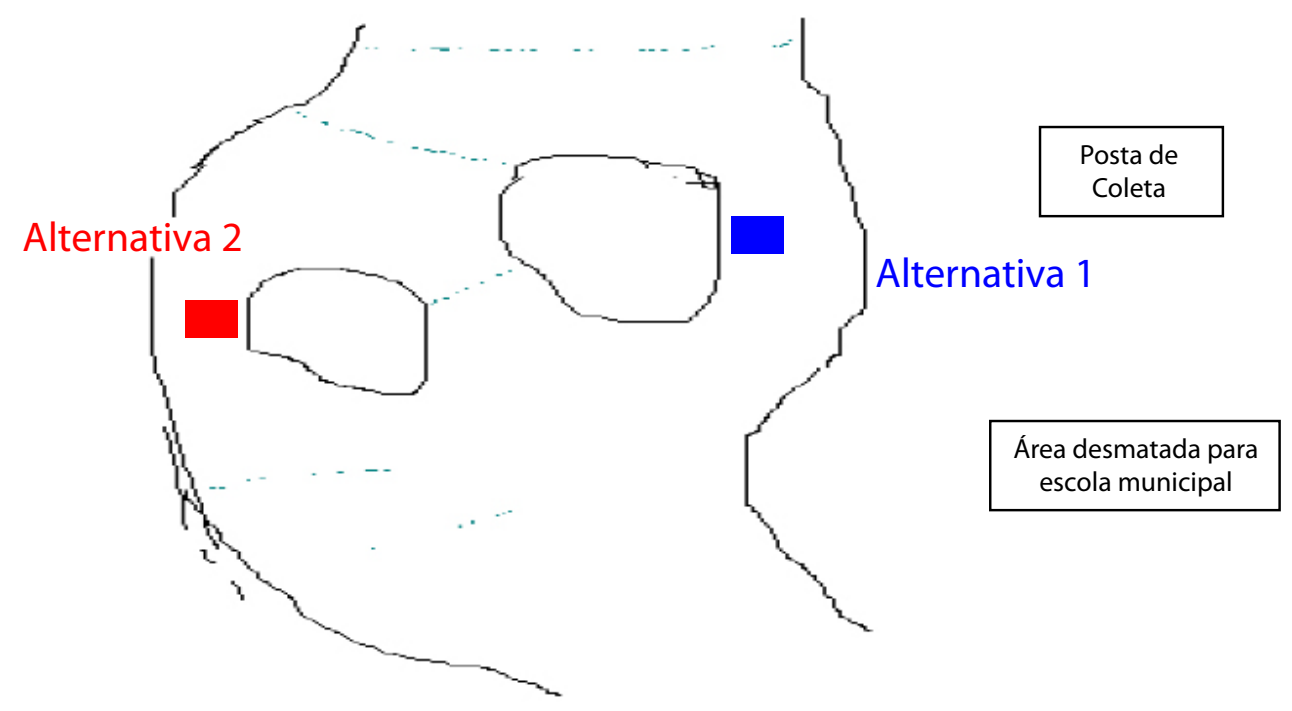

Figura 4 - Localização dos canais da Cachoeira do Caranã e estrutura local

Fonte: Adaptada de Belas, Els e Campos (2002)

área da turbina, $V$ é a velocidade da água e $D$ é o diâmetro da turbina. A Figura 4 representa a localização dos pontos medidos e as estruturas do local.

A Tabela 1 demonstra as diferenças do perfil hidrológico entre os dois pontos possíveis para instalação da turbina hidrocinética na Cachoeira do Caranã.

Tabela 1 - Perfil hidrológico na Cachoeira de Caranã

\begin{tabular}{l|c|c}
\hline Perfil hidrológico & Alternativa 1 & Alternativa 2 \\
\hline $\begin{array}{l}\text { Potência hidráulica } \\
\text { disponível }\end{array}$ & $200 \mathrm{~W}$ & $400 \mathrm{~W}$ a $600 \mathrm{~W}$ \\
Facilidade de acesso & fácil & não tão fácil \\
$\begin{array}{l}\text { Distância do ponto de } \\
\text { coleta }\end{array}$ & $100 \mathrm{~m}$ & $400 \mathrm{~m}$ \\
Canal de navegação & compartilhar & não é utilizado \\
Diâmetro da turbina & $1,2 \mathrm{~m}$ & $0,8 \mathrm{~m}$ ou 1 m \\
Profundidade na seca & $1,2 \mathrm{~m}$ & $0,8 \mathrm{~m}$ \\
Profundidade na cheia & $1,95 \mathrm{~m}$ & $1,3 \mathrm{~m}$ \\
\hline Velocidade da água & $0,7 \mathrm{~m} / \mathrm{s}$ & $1,4 \mathrm{~m} / \mathrm{s}$ \\
\hline
\end{tabular}

Fonte: Adaptado de Belas, Els e Campos (2002)

Verifica-se que a profundidade do rio na época da seca é de 0,8 metros na alternativa 2, altura equivalente ao diâmetro mínimo da turbina proposta para o local. Todavia, Belas, Els e Campos (2002) enfatizam que se algumas pedras no rio forem remanejadas, pode-se canalizar a água para aumentar o volume que incidirá na turbina, o que permitirá, inclusive, aumentar a medida do diâmetro do equipamento que provocará um acréscimo de $50 \%$ na potência gerada. A Figura 5 demonstra o projeto para alternativa 1.

Por ter maior capacidade de potência disponível e viabilidade técnica de construção, optou-se por trabalhar com a alternativa 2, conforme projeto apresentado na Figura 6.

Para análise das condições climáticas optouse por utilizar a classificação de Koeppen. Por esse critério, o clima na Amazônia é considerado quente e úmido, identificado pela letra $A$. Entretanto, a partir da distribuição da temperatura e precipitação durante as estações do ano, podem existir distinções na classificação. É o caso da região em estudo, que pelos parâmetros de Koeppen é identificado pela simbologia Am, ou seja, quente e úmido com uma estação de seca, com temperaturas médias entre $25^{\circ} \mathrm{C}$ e $27^{\circ} \mathrm{C}$. A letra $m$ significa, por essa classificação, o clima de monção - pequena estação de seca durante o ano, normalmente, na primavera. A fase com maior frequência de chuvas está entre o mês de setembro e outubro. As temperaturas médias, 

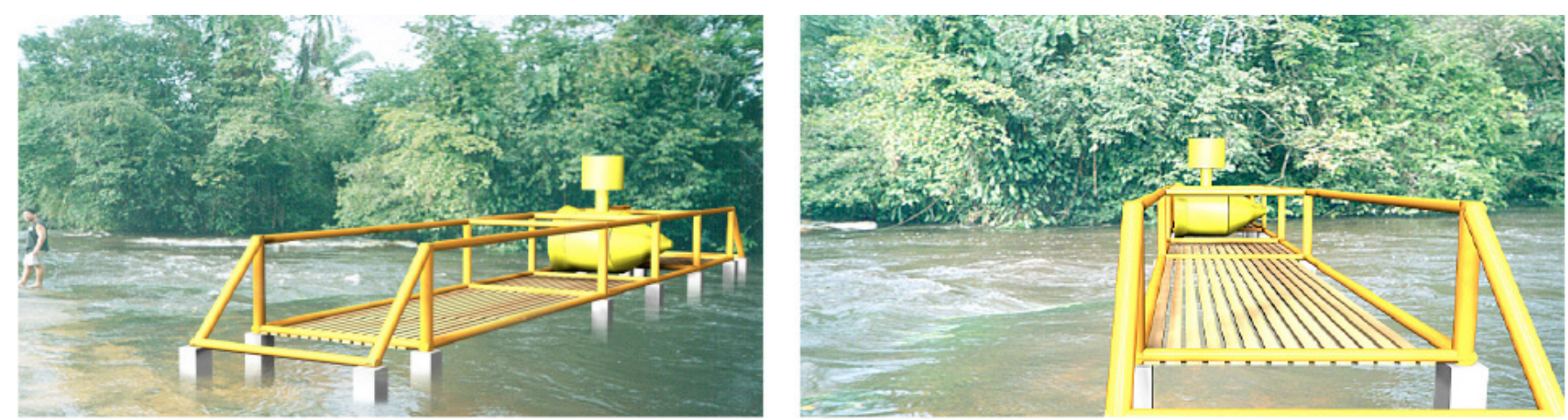

Figura 5 - Projeto da turbina no ponto 1, do Caranã Fonte: Belas, Els e Campos (2002)

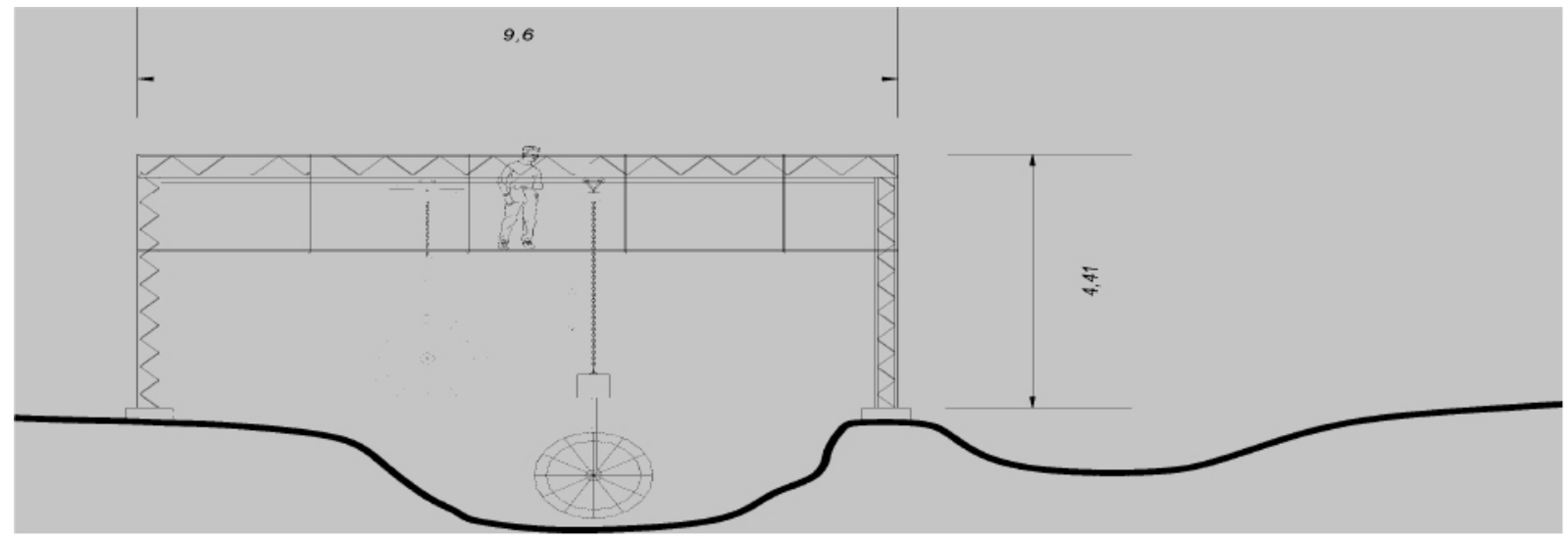

Figura 6 - Projeto da turbina no ponto 2, no Caranã

Fonte: Belas, Els e Campos (2002)

máximas e mínimas são homogêneas durante os meses do ano na região, exatamente como os critérios de classificação de Koeppen (INCRA, 2004).

A descrição das características físicas e químicas do solo, especificamente na área de estudo, são apresentados na Figura 7.

Dos resultados apresentados, chama a atenção o alto índice de acidez do solo. De acordo com o PDA (INCRA, 2004), essa variável, em geral, é o fator limitante e o mais importante a ser superado para a obtenção de melhores produções agrícolas, pois diversos processos produtivos são regulados pela acidez, tais como: intemperização de minerais e formação de argilas, decomposição da matéria orgânica e disponibilidade dos elementos químicos, tanto os essenciais quanto os tóxicos.

Os altos índices de matéria orgânica indicam, de acordo com o PDA (INCRA, 2004), que os solos da região possuem um razoável condicionamento físico-químico, pois a matéria orgânica fornece ao solo uma maior agregação, além de melhorar as condições de fertilidade. Na análise granulométrica, os resultados evidenciam uma textura argilosa a muito argilosa, uma característica que favorece a redução de erosões, assim como se reflete na vegetação, que em geral é de mata densa de alto porte.

As áreas ribeirinhas, bastante comuns no Médio Maracá, também foram analisadas no PDA. Os resultados médios de $\mathrm{pH}$, fósforo, alumínio e matéria orgânica, assim como os resultados granulométricos, indicam um solo com potencial de produção elevado, embora, por ser um ecossistema frágil, requerer cuidados para sua utilização (INCRA, 2004).

As atividades econômicas no assentamento conjugavam agricultura e extrativismo, sendo 

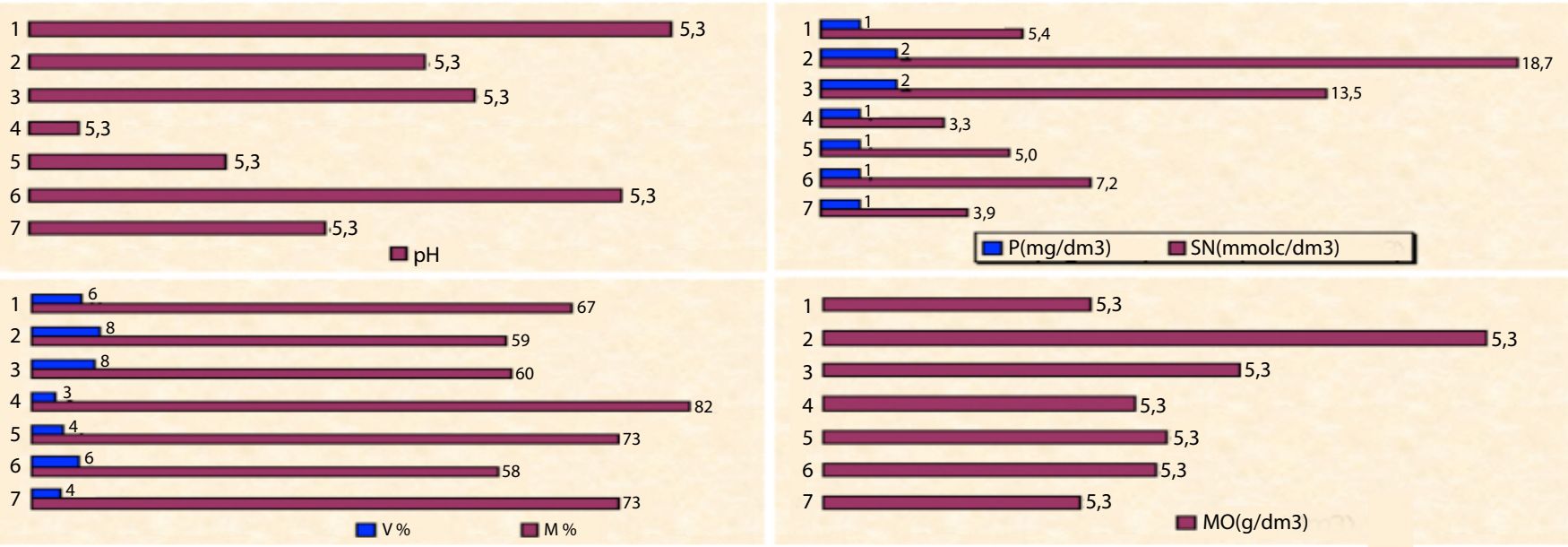

Figura 7 - Níveis de acidez(pH) e fósforo(P), soma de bases trocáveis (SB), saturação por bases (V) e alumínio (M) e teores de matéria orgânica (MO)

Fonte: INCRA (2004)

que em 2005 52\% da população explora ambos, $35,5 \%$ são somente agricultores e 7,7\% não produzem. O extrativismo é uma tradição de família; $70,8 \%$ dos chefes de família responderam que os pais exploravam os recursos naturais da Amazônia e $24,2 \%$ afirmaram que os pais não desenvolviam essa atividade.

Com relação às áreas para o plantio agrícola em terra firme e várzeas, em 2005 87,5\% das famílias possuíam algum tipo de roçado, sendo que: $38,75 \%$ das famílias tinham roça de uma a três tarefas $^{3}, 25,75 \%$, de quatro a seis tarefas, 10,5\%, de sete a nove tarefas, 6,25\%, de dez a 12 tarefas, 2,25\%, de 12 a 15 tarefas e 4,25\%, mais de 15 tarefas. A mandioca era produzida em $73,5 \%$ das unidades de produção, macaxeira em 66,7\%, banana em 64,25\%, limão em 60,75\%, abacaxi em $58,25 \%$, milho em $43,75 \%$ e arroz em $17 \%$.

A exploração da castanha, exercida por 96 famílias do assentamento, atingiu uma produção média por família de 79,58 barricas. Os açaizais, que compreendiam uma área de 249 hectares, foram explorados por 178 famílias diferentes, que colheram 22.983 latas de vinte litros da fruta e

\footnotetext{
3 Tarefa é a medida local para determinar a área plantada e corresponde a $3.030 \mathrm{~m}^{2}$
}

por 34 famílias que extraíram 81.850 cabeças de palmito do açaí. O rio foi utilizado para pesca por $86,25 \%$ das unidades familiares do PAE e a floresta foi local de caça para $63 \%$ das famílias, além ter servido como espaço para a extração de outros recursos naturais, principalmente a macaúba (3.138 toras foram produzidas).

Pelos dados de 2005, ocorreu um aumento de $57,9 \%$ no número de famílias que combinam agricultura com extrativismo e, coerentemente, um decréscimo de 58,8\% na quantidade de famílias que só trabalham na agricultura. Observa-se que os moradores tiveram a iniciativa em diversificar a produção ao longo do tempo. O aumento das atividades agrícolas, em parte, é resultado do acompanhamento técnico e do financiamento da produção que o Instituto de Desenvolvimento Rural do Amapá (RURAP) tem proporcionado na região.

No entanto, o volume produzido é insuficiente para o incremento dessas atividades, bem como para proporcionar uma renda mensal por família que satisfaça as necessidades mínimas de saúde, alimentação, vestuário, entre outros. Mesmo sabendo que há trocas de mercadorias entre a população, inclusive com o comércio local, 52,4\% dos chefes de famílias afirmaram, em 2005, ganhar menos de um salário mínimo por mês. 
A fim de identificar as principais atividades produtivas que incidem na formação da renda mensal das famílias, foi gerado um modelo de regressão com os dados coletados em 2005, onde a variável dependente é renda mensal e as variáveis independentes são: coleta castanha, coleta borracha, coleta cipó, coleta açaí, coleta palmito, coleta madeira, coleta óleo, coleta outros, produz mandioca, produz milho, produz frutas, produz outros. Apenas esta última variável obteve significância $(0,005)$ como preditora de renda, explicando 17,1\% $\left(R^{2}\right)$ da sua variação.

Para apontar o uso econômico da energia de forma a garantir o incremento de renda e também para garantir a manutenção da tecnologia de suprimento, os encontros realizados com os representantes da comunidade demonstraram que alguns moradores entendem que se deve privilegiar o beneficiamento da castanha (secagem, extração de óleo, biscoitos e doces). Outros preferem a instalação de uma fabriqueta para produzirem farinha de mandioca e poucos sugeriram o beneficiamento de outros produtos agroextrativistas. Entretanto, no decorrer do encontro, observou-se que o ideal seria conciliar as duas atividades - beneficiamento da castanha e da mandioca. De acordo com o Morador 1 (2005), "castanha colhe três meses por ano e a agricultura é o ano inteiro".

O representante do Conselho Nacional de Seringueiros (CNS) acredita que o ideal seria atender as duas atividades; todavia, enfatiza que se deve priorizar o beneficiamento da castanha. Essa prioridade se dá pela exigência legal de que todas as fases de produção da castanha sejam certificadas. As instruções normativas de números 12 e 13 de 27 de maio de 2004, do Ministério da Agricultura, Pecuária e Abastecimento (MAPA), regulamenta o processo de certificação das etapas da cadeia produtiva da castanha destinada a exportação. A partir da obrigatoriedade de certificação, os processos produtivos da castanha nas comunidades extrativistas deverão passar por uma estruturação que garanta a origem, a qualidade, transporte, armazenamento, e todo o processo de beneficiamento.

Os dados demonstraram que $79,8 \%$ dos entrevistados extraem castanha e 96,6\% produzem mandioca, ratificando as opiniões dos moradores quanto a agregar valor a essas atividades produtivas. Conceitualmente pode-se dizer que as vantagens comparativas das comunidades do Médio Maracá seriam essas. Nos encontros realizados com os representantes das comunidades constatou-se que havia uma insegurança quanto à capacidade dos próprios moradores em desempenhar, também, a gestão, o beneficiamento e a venda das suas produções. Quanto à possibilidade de se unirem para assumir todo o processo produtivo, ressaltaram que seria viável, desde que houvesse a capacitação de pessoas locais, para gerenciar administrativa e comercialmente uma cooperativa, e dos produtores, para operacionalizar os processos de transformação da matéria-prima.

Os produtores deveriam, na opinião dos entrevistados, formar uma cooperativa, "para tocar em frente o negócio" (Morador 2, 2005). Eles são contra a ATEX-MA assumir qualquer função nesse processo e acreditam que, com o suporte técnico para estruturar a cooperativa e havendo mercado para escoar a produção, poderiam dar sequência ao que foi implementado. Como foi mencionado por um morador, "o negócio sendo bom, os produtores terão que assumir" (Ibidem). O representante do CNS corrobora as opiniões dos moradores: "Como vai mexer com a produção, deve ser uma cooperativa dos produtores. Não deve ser a ATEX-MA, que não tem a função de mexer com a produção. Não pode misturar a gestão da produção com as questões sociais. A ATEX-MA deve trabalhar com a política. Agora é possível fazer a cooperativa, a capacitação dos moradores, usando os recursos que existem. Existem recursos humanos para fazer a cooperativa; é necessário treinamento e parcerias". 
A necessidade de capacitação dos moradores conduz para os serviços sociais produzidos na comunidade. Sobre a existência de recursos humanos para participar da consolidação de uma cooperativa dos produtores, o entrevistado refere-se à formação dos alunos pela Escola Família Rural de Maracá. Há quatro anos em atividade, a escola adota a pedagogia da alternância como metodologia de ensino. Os alunos passam 15 dias na escola e 15 dias em casa. Nesse período, desenvolvem tarefas juntamente com seus familiares, compartiIhando o conhecimento com a família. De acordo com o representante do CNS "a escola trabalha contra o êxodo rural, preocupa-se em internalizar o conhecimento e criar a cultura do associativismo, que deverá se expandir para a comunidade. Deve priorizar os valores locais, por isso tenho brigado com os professores, que às vezes renegam as coisas locais, pois pensam em valores urbanos".

No encontro com representantes da Escola Família Rural foi possível verificar o empenho de se trabalhar com o aluno dentro da sua realidade social, econômica e ambiental. Atuando de quinta a oitava série, a escola trabalha com um tema gerador diferente por um bimestre por ano, além das disciplinas básicas. Isso irá formar, ao término do curso, o Caderno da Realidade. Na quinta série trabalha-se com a família como tema gerador, abordando a participação do jovem na comunidade, a origem e a história da família. Na sexta série o tema é o extrativismo, que enfoca o extrativismo animal e vegetal, a vida da família na floresta e a coleta e comercialização dos produtos da floresta. Na sétima série tem-se como tema o social, que compreende assuntos como prostituição, doenças sexualmente transmissíveis, gravidez, tabagismo, alcoolismo e organizações sociais (cooperativa, sindicato e associações). Na oitava série, o tema gerador é a agricultura e os processos de cultivos.

Atualmente existem três escolas no Médio Maracá, sendo uma mantida pelo Governo do Estado do Amapá (GEA), uma pela prefeitura de
Mazagão e a Escola Família Rural, responsabilidade do CNS. Há ainda uma escola em Maruim, Pancada do Maracá e Varador, todas sob a responsabilidade da prefeitura. Quanto à avaliação da infraestrutura e da qualidade de ensino das escolas mantidas pela prefeitura e GEA, nessas áreas, respectivamente, $50 \%$ e $58 \%$ dos chefes de família acreditam que são boas. O ensino da Escola Família obteve melhor avaliação em 2005, sendo que 62,7\% dos entrevistados qualificaram-no como bom. Com relação à frequência de alunos nas escolas, o maior índice é na faixa etária de seis a catorze anos, com 31,7\%. Acima de 20 anos, apenas $15,4 \%$ da população frequenta a escola.

À época do levantamento (FILOCREÃO; LITTLE, 1994), havia três postos de saúde na região. Em 2005 existia apenas um posto de saúde, sendo que $26,1 \%$ dos entrevistados avaliaram o atendimento como ruim, $20,5 \%$ avaliaram como regular e $25,0 \%$ avaliaram como bom. A existência de medicamentos e a presença de enfermeiros e agente de saúde no local são incipientes. Além disso, as entrevistas demonstraram que há uma preocupação quanto à disponibilidade e qualidade do exame de lâminas para detecção de malária. As condições sanitárias na comunidade, em geral, eram agravantes para a saúde da população, pois de acordo com o levantamento, 68\% das famílias não possuíam fossa sanitária, 29,5\% possuíam fossa negra, e somente $1,5 \%$ possuía fossa séptica. A situação piora ao constatar-se que $56,2 \%$ das residências tinham como fonte de abastecimento de água o rio.

As doenças com maior incidência eram a diarreia, atingindo $59 \%$ das famílias, a malária, em $46,5 \%$, e as verminoses, em 37,5\%. De acordo com o levantamento (Ibidem), essa realidade era consequência das condições higiênico-sanitárias aliadas ao processo de desnutrição em algumas comunidades, além da falta de combate (através de dedetização) contra o transmissor da malária. Em 2005 percebe-se que a população do Médio Maracá tem se preocupado com a questão higiênico-sanitária, 
tanto que houve uma diminuição de 30,6\% no número de residências sem esgotamento sanitário. Esse fato torna-se mais importante ao se verificar que nas duas pesquisas $56,2 \%$ dos entrevistados apontaram o rio como a única fonte de abastecimento de água.

As informações indicam menores quantidades de dejetos humanos depositados no rio, o que contribui para o decréscimo dos índices de diarreia e verminoses na população. Ainda são necessárias ações para motivar a construção de banheiros nas residências, pois em 2005 66,3\% dos entrevistados responderam que não possuem sanitários em suas casas ou propostas para o tratamento do lixo, já que $55,1 \%$ dos chefes de família afirmaram queimá-lo.

Como apresentado neste diagnóstico, as ações urgentes relacionadas aos objetivos do trabalho, ditas anteriormente, são:

- Para o subsistema de produção econômica, o diagnóstico indicou a estruturação de uma cooperativa para o beneficiamento da castanha e da mandioca (aproveitando as condições do solo e clima). Para isso foi necessário elaborar um plano de negócios, garantindo um estudo: i) dos aspectos legais que envolvem a constituição e manutenção da organização; ii) da definição dos atores e/ou representantes locais que irão participar da organização; iii) do mercado (concorrentes, fornecedores, consumidores); iv) da estrutura organizacional necessária para a gestão; v) das formas e parcerias para a capacitação de recursos humanos; vi) da viabilidade financeira; vii) das parcerias e fontes de recursos financeiros que possam ser explorados; viii) definição dos instrumentos de acompanhamento para avaliação de resultados.

- Para o subsistema de provimento de serviços sociais, o diagnóstico indicou, por um lado, a necessidade de se criarem condições para o acondicionamento refrigerado dos insumos para exame de malária. Por outro lado, a alfabetização dos adultos acima de 20 anos. Com relação à alfabetização dos adultos, foi formada uma turma com quinze alunos que iniciaram os estudos em 2008 no período noturno, em uma instalação na comunidade.

\section{CONCLUSÃO}

Diante do desafio da universalização de energia elétrica, o Estado, como uma instância jurídico -política, assume o papel não somente de prover a geração de energia em comunidades isoladas, mas a responsabilidade de preparar os atores locais para utilizá-la na promoção do desenvolvimento local sustentável. Para isso são necessárias metodologias de gestão que permitam a participação da comunidade em todo processo e sistêmica, considerando as relações e práticas sociais e privilegiando as funções necessárias para o processo de desenvolvimento.

A GSPL conjuga a participação e o enfoque sistêmico e em especial demonstra as dimensões de uma comunidade que devem ser estudadas. Caracteriza-se também por ser um processo contínuo de fases interdependentes (diagnóstico, prognósticos, formulação de propostas, implantação de ações, monitoramento, avaliação e retroalimentação do processo).

O trabalho permitiu elaborar as ações necessárias para o uso produtivo da energia pela comunidade de acordo com suas próprias perspectivas. Além disso, por seu caráter interdisciplinar, não se restringiu a questões econômicas, mas também possibilitou formular ações sociais, em especial na educação e saúde locais.

O estudo de campo indicou que os atores são capazes de confrontar e desmistificar pressupostos técnicos e anseiam por um apoio que os possibilite melhorar sua vida e de sua família, estão dispostos a 
se organizar e assumir responsabilidades (desde que devidamente preparados) e podem, após uma fase de aproximação, acreditar e participar de um processo de planejamento e gestão. Entretanto, em alguns momentos podem ser ansiosos por atitudes paternalistas e assistencialistas, submissos ao poder local e criarem um ambiente de desconfiança, o que exige do técnico muita atenção no trato de todo o processo.
As propostas não se esgotam aqui, mas se restringem aos limites do artigo. Vale ressaltar que o diagnóstico realizado no Médio Maracá permitiu a formulação de diversas outras ações, independentes da inserção de energia elétrica. Ações que impactaram positivamente o uso dos recursos naturais, a estrutura política local e a prestação de serviços de saúde.

\section{REFERÊNCIAS}

ATHAYDE, M.; SILVÉRIO, J.; BRASIL, A. C. P. Avaliação da sustentabilidade de sistema de energia em comunidades isoladas. In: ANAIS DO XVI CONGRESSO BRASILEIRO DE ENGENHARIA MECÂNICA, São Paulo - Brasil, 2001.

BELAS, C., ELS, R. H. van, CAMPOS, C. Projeto Piloto de Micro Central Hidrocinética para geração de energia elétrica na Reserva Extrativista do Vale do Rio Maracá: Relatório de Levantamento e Projeto Técnico, Secretaria de Coordenação da Amazônia MMA. Brasília, 2002.

BERTALANFFY, L. V. General system theory. Nova York: George Braziller, 1976. 296 p.

BRASIL. Lei n ${ }^{\circ}$ 10.438, de 26 de abril de 2002. Disponível em: <http://www.planalto.gov.br/CCIVIL_03/leis/2002/ L10438.htm>. Acesso em: 25 dez 2004.

BRASIL. Ministério das Minas e Energia. Programa nacional de universalização do acesso e uso da energia elétrica - manual de operacionalização. Disponível em: < http://luzparatodos.mme.gov.br/ luzparatodos/downloads/MANUAL \%20DE\%20 OPERACIONALIZA \% C 3\% 87\% C 3\% 830\% 20 LpT\%202011-2014.pdf > Acesso em: 20 dez. 2004.

BUARQUE, S. C. Construindo o desenvolvimento local sustentável. Rio de Janeiro: Garamond, 2002.
CAPRA, F. A teia da vida. São Paulo: Cultrix, 1997.

CASSIOLATO J. E.; LASTRES, H. M. M. O foco em arranjos produtivos e inovativos locais de micro e pequenas empresas. In: LASTRES, H. M. M; CASSIOLATO, J. E.; MACIEL, M. L. (Orgs.). Pequena empresa: cooperação e desenvolvimento local. Rio de Janeiro: Relume Dumará, 2003.

DAFT, R. L. Administração. 4. ed. Rio de Janeiro: LTC, 1999.

DEMO, P. Planejamento participativo. In: Ministério da Educação e Cultura (Org.). Subsídio ao planejamento participativo. Brasília: MEC/DDD, 1980.

ELS, R. H. van; BELAS C.; CAMPOS, C. Projeto piloto de micro central hidrocinética para geração de energia elétrica na reserva extrativista do Vale do Rio Maracá: Relatório de Levantamento e Projeto Técnico. Brasília: Secretaria de Coordenação da Amazônia, 2002.

ELS, R. H. van; CAMPOS, C.; HENRIQUES, A.; BALDUINO, L. Hydrokinetic turbine for isolated villages. PCH Notícias SHP News, Itajubá, v. 19, p. 24-25, 2003.

FILOCREÃO, M.; LITTLE, P. Relatório sócio-econômico dos PAES MARACÁ I, II e III. Brasília: IEA e WWF, 1994.

FONTES, B. A. S. M.; EICHNER, K. Sobre a estruturação de redes sociais em associações voluntárias: estudo empírico 


\section{REFERÊNCIAS}

de organizações não governamentais da cidade do Recife. Sociedade e Estado, Brasília, v. 16, n. 1-2, dez. 2001.

GEORGESCU-ROEGEN, N. The entropy law and economic problem. In: DALY, H.; TOWNSEND, K. Valuing the earth: economics, ecology, ethics. Massachusetts: The MIT Press Cambridge, 1993.

INCRA. Plano de desenvolvimento do PAE Maracá. Macapá: INCRA-FUNDAP, 2004.

LEFF, E. Saber ambiental. Petrópolis: Vozes, 2001.

MADURO-ABREU, A. Por uma gestão sistêmica e participativa local: o caso da vila de Maracá. Dissertação (Mestrado). Centro de Desenvolvimento Sustentável, Universidade de Brasília, Brasília. 2005.

MATUS, C. Política, planejamento e governo. Brasília: IPEA, 1997.

MEGGINSON, L. C.; MOSLEY, S.; PIETRI JR. P. H. Administração: conceitos e aplicações. São Paulo: Harbra, 1998.

MÜLLER, G. Região: descentralização na globalização. Revista REDES, Santa Cruz do Sul, v. 5, n. 2, p. 9-25, 2000.

PECQUEUR, B. Le développement local. 2. ed. Paris: Syros, 2000.

PIRES, E. L. S. As lógicas territoriais do desenvolvimento: diversidades e regulação. Interações (Campo Grande), Campo Grande, v. 8, n. 2, set. 2007.
PIRES, E.; MÜLLER, G.; VERDI, A. Instituições, territórios e desenvolvimento local: delineamento preliminar dos aspectos teóricos e morfológicos. In: Geografia. Associação de Geografia Teorética, Rio Claro, v. 31, n. 3, p. 437-454, set./dez. 2006.

PROJETO PROMOS/SEBRAE/BID. Versão 2.0: CAPORALI, R.; VOLKER, P. (Org.). Metodologia de desenvolvimento de arranjos produtivos locais. Brasília: SEBRAE, 2004.

PUTNAM, R. D.; LEONARDI, R.; NANETTI, R. Y. Comunidade e democracia: a experiência da Itália moderna. 3. ed. Rio de Janeiro: FGV, 2002.

REDCLIFT, M. Sustainable development and popular participation: a framework for analysis. In: GHAl, D.; VIVIAN, J. M. (Eds.). Grassroots-environmental action: people participation in sustainable development. London: Routledge, 1995.

SACHS, I. Estratégias de transição para o século XXI. São Paulo: Studio Nobel/FUNDAP, 1993.

Caminhos para o desenvolvimento sustentável. Rio de Janeiro: Garamond, 2000.

Inclusão social pelo trabalho: desenvolvimento humano, trabalho decente e o futuro dos empreendedores de pequeno porte. Rio de Janeiro: Garamont, 2003.

VAN ELS, R. H.; VIANNA, J. N.; BRASIL Jr. A. C. P. The Brazilian experience of rural electrification in the Amazon with decentralized generation: the need to change the paradigm from electrification to development. Renewable and Sustainable Energy Reviews. v. 16, n. 3, p. 1450-1461, 2012. 